University of South Carolina

Scholar Commons

2000

\title{
Computational Fluid Dynamics Modeling of a Lithium/Thionyl Chloride Battery with Electrolyte Flow
}

\author{
W. B. Gu \\ Pennsylvania State University \\ C. Y. Wang \\ Pennsylvania State University \\ John W. Weidner \\ University of South Carolina - Columbia, weidner@engr.sc.edu \\ Rudolph G. Jungst \\ Ganesan Nagasubramanian \\ Follow this and additional works at: https://scholarcommons.sc.edu/eche_facpub \\ Part of the Chemical Engineering Commons
}

\section{Publication Info}

Journal of the Electrochemical Society, 2000, pages 427-434.

(c) The Electrochemical Society, Inc. 2000. All rights reserved. Except as provided under U.S. copyright law, this work may not be reproduced, resold, distributed, or modified without the express permission of The Electrochemical Society (ECS). The archival version of this work was published in the Journal of the Electrochemical Society.

http://www.electrochem.org/

Publisher's link: http://dx.doi.org/10.1149/1.1393213

DOI: $10.1149 / 1.1393213$

This Article is brought to you by the Chemical Engineering, Department of at Scholar Commons. It has been accepted for inclusion in Faculty Publications by an authorized administrator of Scholar Commons. For more information, please contact digres@mailbox.sc.edu. 


\title{
Computational Fluid Dynamics Modeling of a Lithium/Thionyl Chloride Battery with Electrolyte Flow
}

\author{
W. B. Gu, ${ }^{\mathrm{a}, *}$ C. Y. Wang, ${ }^{\mathrm{a}, * *, \mathrm{z}}$ John W. Weidner, ${ }^{\mathrm{b}, * *}$ Rudolph G. Jungst, ${ }^{\mathrm{c}, * *}$ and \\ Ganesan Nagasubramanian ${ }^{\mathfrak{c}, * *}$
}

\author{
${ }^{a}$ GATE Center for Advanced Energy Storage, Department of Mechanical Engineering, Pennsylvania State University, University \\ Park, Pennsylvania 16802, USA \\ ${ }^{b}$ Center for Electrochemical Engineering, Department of Chemical Engineering, University of South Carolina, Columbia, \\ South Carolina 29208, USA \\ ${ }^{c}$ Lithium Battery Research and Development Department, Sandia National Laboratories, Albuquerque, New Mexico 87185, USA
}

\begin{abstract}
A two-dimensional model is developed to simulate discharge of a lithium/thionyl chloride primary battery. As in earlier one-dimensional models, the model accounts for transport of species and charge, and electrode porosity variations and electrolyte flow induced by the volume reduction caused by electrochemical reactions. Numerical simulations are performed using a finite volume method of computational fluid dynamics. The predicted discharge curves for various temperatures show good agreement with published experimental data, and are essentially identical to results published for one-dimensional models. The detailed two-dimensional flow simulations show that the electrolyte is replenished from the cell head space predominantly through the separator into the front of the cathode during most parts of the discharge, especially for higher cell temperatures.

(c) 2000 The Electrochemical Society. S0013-4651(99)06-102-9. All rights reserved.
\end{abstract}

Manuscript submitted June 21, 1999; revised manuscript received September 30, 1999.

This paper is a continuation of the recent series of work to explore computational fluid dynamics (CFD) techniques in conjunction with experimentation for fundamental battery research. The application of interest in this work is a lithium/thionyl chloride primary battery. As a power source, this battery has many desirable characteristics such as high energy and power densities, high operating cell voltage, excellent voltage stability over $95 \%$ of the discharge, and a large operating temperature range. As such, there has been a number of one-dimensional modeling studies ${ }^{1-6}$ in the literature. Modeling efforts by Szpak et al. ${ }^{1}$ and $\mathrm{Cho}^{2}$ focused on the battery's high-rate discharge and the ensuing thermal behavior. Other modeling efforts employed concentrated solution theory and porous electrode theory in the various regions of the cell (e.g., separator, porous cathode) to develop one-dimensional models of the battery. ${ }^{3-6}$ These models examined utilization issues at low to moderate currents, but they differ in how the excess electrolyte was treated.

In the lithium/thionyl chloride cell, the solvent is also the reactant, and the volume it occupies is more than that of the reaction products. Therefore, more electrolyte is placed in the cell than can occupy the initial void volume of the separator and porous cathode. The excess electrolyte resides in the head space volume above the active regions. Due to the one-dimensional nature of their models, Tsaur and Pollard ${ }^{3}$ and Evans et al. ${ }^{4}$ introduced a fictitious reservoir region between the separator and the porous cathode. In these models, the electrolyte fills uniformly from this reservoir region, through the separator, and into the cathode. In contrast, Jain et al. ${ }^{5,6}$ modified the one-dimensional equations so that the electrolyte flows from the head space directly into the porous cathode, thus replicating flow in a second, perpendicular direction. An advantage of this latter approach is that the model can predict the drying of the cell due to insufficient electrolyte loading. While these one-dimensional models are simple and efficient at predicting the discharge of a $\mathrm{Li} / \mathrm{SOCl}_{2}$ battery, a multidimensional model fully accounting for the electrolyte flow without making ad hoc approximations is deemed valuable to gain a more fundamental understanding of the processes that occurr in this battery system. The present paper describes such a model and a finite-volume method of CFD to simulate a $\mathrm{Li} / \mathrm{SOCl}_{2}$ battery in the operating regime of low to intermediate discharge rates. The model uses the physical parameters estimated from experimental data ${ }^{6}$ to predict discharge curves accurately at various temperatures.

\footnotetext{
* Electrochemical Society Student Member.

** Electrochemical Society Active Member.

z E-mail: cxw31@psu.edu
}

\section{Numerical Model}

Description of a $\mathrm{Li} \mathrm{SOCl}_{2}$ system.-A schematic of a lithium/ thionyl chloride $\left(\mathrm{Li} / \mathrm{SOCl}_{2}\right)$ cell is shown in Fig. 1. The system is identical to the one studied most recently by Jain et al. ${ }^{5,6}$ Basically, the cell consists of a lithium foil anode and $\mathrm{LiCl}$ film, a separator (glass matting), and a porous carbon cathode support with the electrolyte being lithium tetrachloraluminate $\left(\mathrm{LiAlCl}_{4}\right)$ salt dissolved in the thionyl chloride $\left(\mathrm{SOCl}_{2}\right)$. The passive lithium chloride $(\mathrm{LiCl})$ film forms on the lithium foil due to lithium corrosion, namely

$$
4 \mathrm{Li}+2 \mathrm{SOCl}_{2} \rightarrow 4 \mathrm{LiCl}(\mathrm{s})+\mathrm{SO}_{2}+\mathrm{S}
$$

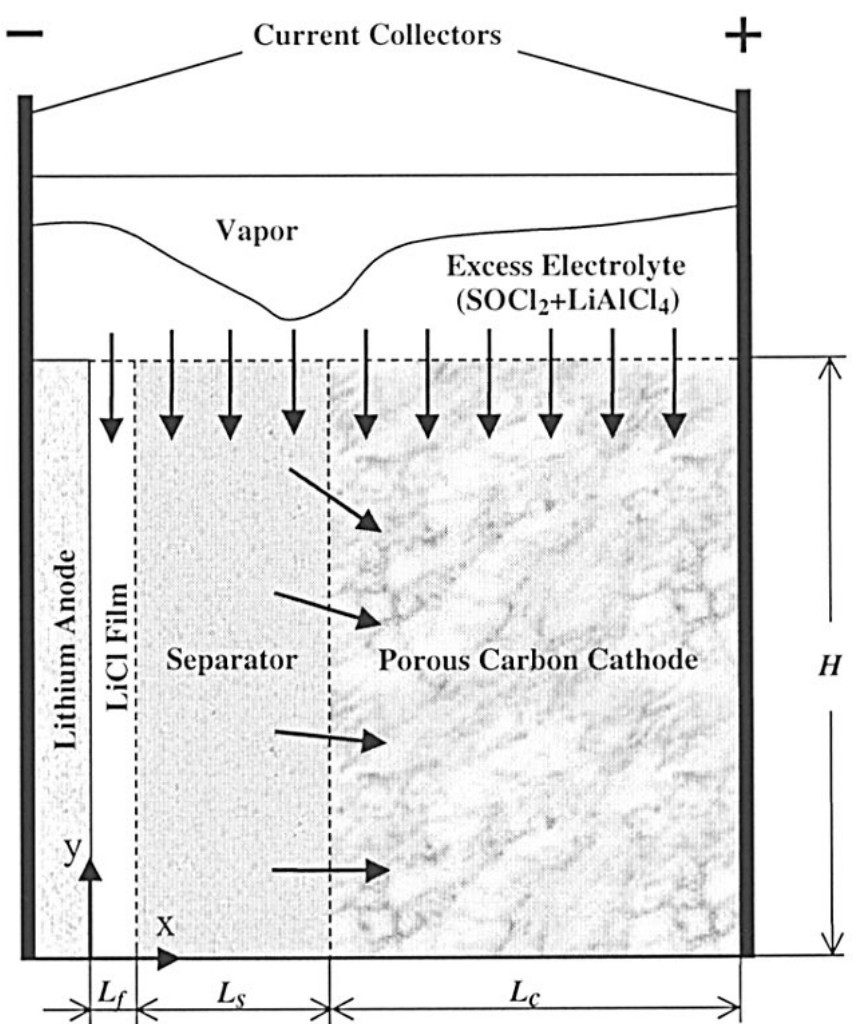

Figure 1. Schematic of a $\mathrm{Li} / \mathrm{SOCl}_{2}$ cell. 
The $\mathrm{LiCl}$ film can further be divided into two subregions: a relatively thin, compact film adjacent to the $\mathrm{Li}$ anode, known as the solidelectrolyte interface (SEI), and a much thicker, porous $\mathrm{LiCl}$ film formed next to the SEI, known as the secondary porous layer. ${ }^{7,8}$ No reaction occurs in the secondary layer, and its matrix is not conducting; thus, it behaves much like the separator. place

During discharge, the following electrochemical reactions take

Anode

$$
\mathrm{Li}(\mathrm{s}) \rightarrow \mathrm{Li}^{+}+\mathrm{e}^{-}
$$

Cathode $4 \mathrm{Li}^{+}+4 \mathrm{e}^{-}+2 \mathrm{SOCl}_{2} \rightarrow 4 \mathrm{LiCl}(\mathrm{s})+\mathrm{SO}_{2}+\mathrm{S}$

That is, the lithium is oxidized at the anode and $\mathrm{SOCl}_{2}$ is reduced at the cathode, followed by precipitation of $\mathrm{LiCl}$ in the cathode. Significant volume reduction occurs during Reaction 3 due to the larger molar volume of $\mathrm{SOCl}_{2}$ compared to the $\mathrm{LiCl}$ precipitate, thereby resulting in electrolyte flow from the top head space volume into the cell (see Fig. 1).

Assumptions.-The following assumptions are invoked in this work; they have been justified by Jain et al. ${ }^{6}$ for cells discharged at low to intermediate rates.

1. $\mathrm{LiCl}$ precipitation occurs completely and instantaneously at the cathode.

2. The cathode thickness remains constant (but a higher cathode thickness is assumed initially to account for swelling).

3. The porous $\mathrm{LiCl}$ film on the anode has a constant thickness and porosity.

4. The solid-electrolyte interface (SEI) is treated as the $\mathrm{Li}$ anode surface and its effect on the cell performance is accounted for via the electrode kinetics.

5. The electrolyte is treated as a binary solution with constant properties, although the $\mathrm{LiAlCl}_{4}$ salt concentration changes during discharge. The effects of products $\mathrm{S}$ and $\mathrm{SO}_{2}$ are implicitly included in the properties of the solvent.

6. The cell remains isothermal.

7. Effects of double-layer charging and self-discharge are ignored.

Governing equations.-Based on the above-stated assumptions, a two-dimensional model for $\mathrm{Li} / \mathrm{SOCl}_{2}$ batteries can be derived from the general modeling framework previously developed by Wang et al. ${ }^{9}$ Specifically, the present model consists of equations governing conservation of species, charge, mass and momentum in electrolyte and electrode matrix phases, respectively.

Applying the general species conservation equation in Table I of Wang et al. ${ }^{9}$ to the species of interest in the $\mathrm{Li} / \mathrm{SOCl}_{2}$ system, one obtains

$$
\frac{\partial \epsilon_{\mathrm{e}} c}{\partial t}+\nabla \cdot(\mathbf{v} c)=\nabla \cdot\left(D^{\mathrm{eff}} \nabla c\right)+\frac{1-t_{+}^{0}}{F} j
$$

for $\mathrm{Li}^{+}$, and

$$
\frac{\partial \epsilon_{\mathrm{e}} c_{\mathrm{o}}}{\partial t}+\nabla \cdot\left(\mathbf{v} c_{\mathrm{o}}\right)=\nabla \cdot\left(D^{\mathrm{eff}} \nabla c_{\mathrm{o}}\right)+\frac{1}{2 F} j_{\mathrm{o}}
$$

for $\mathrm{SOCl}_{2}$. Here, $\nabla=\partial / \partial x i+\partial / \partial y j$ is for the two-dimensional Cartesian coordinate system, $c$ is the concentration of a species in the electrolyte, and $j$ is the volumetric reaction current resulting in production or consumption of the species. Subscript o denotes the solvent $\mathrm{SOCl}_{2}, \epsilon_{\mathrm{e}}$ is the volume fraction of the liquid electrolyte, $\mathbf{v}$ is the superficial electrolyte velocity, $D^{\text {eff }}$ is the effective diffusivity of the electrolyte, and $t_{+}^{0}$ is the transference number of lithium ion with respect to the volume-average velocity.

The reaction currents are given by

$$
j= \begin{cases}a_{1} \bar{i}_{\mathrm{n} 1} & \text { at anode } \\ a_{2} \bar{i}_{\mathrm{n} 2} & \text { at cathode }\end{cases}
$$

Table I. Values of parameters used in the simulations. The viscosity, $\mu$, was obtained from Ref. 14, and all other parameters were obtained from Ref. 6.

Symbol Value Unit Description

Geometric

A 180

$a^{\mathrm{o}} \quad 1000$

$L_{\mathrm{f}}$

$L_{\mathrm{c}}$

$\epsilon_{\mathrm{c}}$

$\epsilon$

$\underset{\epsilon_{\mathrm{s}}^{\mathrm{o}}}{\epsilon^{\mathrm{O}}}$

0.95
0.835

Chemical

$\hat{V}$

$\hat{V}$

$\hat{V}_{\mathrm{o}}$

$\hat{V}_{\text {LiCl }}$

Transport

$t_{+}^{\circ}$

$D$

K

$\mu$

$\kappa$

$\sigma$

Kinetic

$i_{\text {o1,ref }}$

$i_{\text {o2,ref }}$

Eq. A-1

$\alpha_{\mathrm{a} 1}, \alpha_{\mathrm{c} 1}$

$1 \times 10^{-5}$

$1 \times 10^{-2}$

Eq. A-

45.5

4.445

0.001

0.023

0.085

0.95

0.05

0.001

$\mathrm{mol} / \mathrm{cm}^{3}$ Initial concentration of electrolyte

$\mathrm{cm}^{3} / \mathrm{mol}$ Partial molar volume of $\mathrm{LiAlCl}_{4}$ salt

$\mathrm{cm}^{3} / \mathrm{mol}$ Partial molar volume of $\mathrm{SOCl}_{2}$ solvent

$\mathrm{cm}^{3} / \mathrm{mol}$ Partial molar volume of $\mathrm{LiCl}$ solid

Transference number of lithium ion

Molecular diffusivity of electrolyte

Permeability of porous separator

Dynamic viscosity of electrolyte

Ionic conductivity of electrolyte

Electronic conductivity of solid matrix

$\alpha_{\mathrm{a} 2}, \alpha_{\mathrm{c} 2} \quad 1.7,0.3$

$U_{1, \text { ref }} \quad-E$

0

$U_{2 \text {,ref }}$

$$
0
$$

E

Eq. A-5 $d E / d T \quad 2.28 \times 10^{-4} \quad \mathrm{~V} / \mathrm{K}$

$\mathrm{A} / \mathrm{cm}^{2}$

Exchange current density of anode reaction

Exchange current density of cathode reaction

Transfer coefficients of anode reaction

Transfer coefficients of cathode reaction

Open-circuit potential of anode reaction

Open-circuit potential of cathode reaction

Cell open-circuit voltage

Temperature dependence of $E$

and

$$
j_{\mathrm{o}}=\left\{\begin{aligned}
0 & \text { at anode } \\
a_{2} \bar{i}_{\mathrm{n} 2} & \text { at cathode }
\end{aligned}\right.
$$

where the transfer current densities are expressed by the ButlerVolmer equation as

$$
\bar{i}_{\mathrm{n} 1}=i_{\mathrm{o} 1, \mathrm{ref}}\left[\exp \left(\frac{\alpha_{\mathrm{a} 1} F}{R T} \eta_{1}\right)-\left(\frac{c}{c_{\text {ref }}}\right) \exp \left(-\frac{\alpha_{\mathrm{c} 1} F}{R T} \eta_{1}\right)\right]
$$

and 


$$
\bar{i}_{\mathrm{n} 2}=i_{\mathrm{o} 2, \operatorname{ref}}\left[\exp \left(\frac{\alpha_{\mathrm{a} 2} F}{R T} \eta_{2}\right)-\left(\frac{c}{c_{\text {ref }}}\right)^{2}\left(\frac{c_{\mathrm{o}}}{c_{\mathrm{o}, \mathrm{ref}}}\right) \exp \left(-\frac{\alpha_{\mathrm{c} 2} F}{R T} \eta_{2}\right)\right]
$$

In the above, the surface overpotential that drives the electrochemical reaction at the electrode/electrolyte interface is defined as

$$
\eta_{\mathrm{j}}=\phi_{\mathrm{s}}-\phi_{\mathrm{e}}-U_{\mathrm{j}, \mathrm{ref}} \quad j=1,2
$$

where $\phi$ is the electric potential; subscripts s and e denoting solid and liquid phases, respectively. The last term, $U_{\mathrm{j}, \text { ref }}$, is the open-circuit potential of electrode reaction $j$ measured using a reference electrode under the reference conditions.

In Eq. 6 and 7, $a$ is the electrochemically active surface area per unit volume, with subscripts 1 and 2 denoting anode and cathode, respectively. While $a_{1}$ is assumed to be constant, $a_{2}$ varies during discharge due to $\mathrm{LiCl}$ precipitation via the following correlation ${ }^{10}$

$$
a_{2}=a_{2}^{\mathrm{o}}\left[1-\left(\frac{\epsilon_{\mathrm{e}}^{\mathrm{o}}-\epsilon_{\mathrm{e}}}{\epsilon_{\mathrm{e}}^{\mathrm{o}}}\right)^{\zeta}\right]
$$

where superscript o represents initial values. The exponent $\zeta$ is an empirical parameter used to describe the morphology of the electroactive surface. ${ }^{10}$

The effective diffusivity of species in the electrolyte accounting for the effects of porosity and tortuosity is evaluated via the Bruggeman correction

$$
D^{\mathrm{eff}}=\epsilon_{\mathrm{e}}^{1.5} D
$$

where $D$ is the diffusion coefficient of the electrolyte. has

Applying the potential equations in Table I of Wang et al., ${ }^{9}$ one

$$
\nabla \cdot\left(\kappa^{\mathrm{eff}} \nabla \phi_{\mathrm{e}}\right)+\nabla \cdot\left(\kappa_{\mathrm{D}}^{\mathrm{eff}} \nabla \ln c\right)+j=0
$$

for the liquid phase potential and

$$
\nabla \cdot\left(\sigma^{\mathrm{eff}} \nabla \phi_{\mathrm{s}}\right)-j=0
$$

for the solid phase potential. Here, $\kappa^{\text {eff }}$ is the effective ionic conductivity of the electrolyte, and $\sigma^{\text {eff }}$ is the effective electronic conductivity of the solid matrix, both of which can be evaluated by a similar expression to Eq. 12. The effective diffusional ionic conductivity, $\kappa_{\mathrm{D}}^{\text {eff }}$, is given by

$$
\kappa_{\mathrm{D}}^{\mathrm{eff}}=\frac{2 R T \kappa^{\mathrm{eff}}}{F}\left[t_{+}^{\mathrm{o}}-1+\frac{c}{2 c_{\mathrm{o}}}\right]
$$

for the reactions described by Eq. 2 and 3.

Mass balance for the solid phase yields

$$
\frac{\partial \epsilon_{\mathrm{s}}}{\partial t}=-\frac{j_{\mathrm{o}}}{F} \hat{V}_{\mathrm{LiCl}}
$$

where $\epsilon_{\mathrm{s}}$ is the volume fraction of the solid phase and $\hat{V}_{\mathrm{LiCl}}$ is the partial molar volume of the species $\mathrm{LiCl}$. Equation 16 implies that the volume fraction of the solid phase at the cathode increases due to the precipitation of an $\mathrm{LiCl}$ film upon reaction (here $j_{\mathrm{o}}<0$ ), while it remains constant within the anode.

For the binary electrolyte it follows that

$$
c \hat{V}+c_{\mathrm{o}} \hat{V}_{\mathrm{o}}=1
$$

where $\hat{V}$ or $\hat{V}_{\mathrm{o}}$ are the partial molar volumes of the electrolyte salt $\left(\mathrm{LiAlCl}_{4}\right)$ and the solvent $\left(\mathrm{SOCl}_{2}\right)$, respectively. Adding Eq. 4 multiplied by $\hat{V}$ and Eq. 5 multiplied by $\hat{V}_{\mathrm{o}}$, and making use of Eq. 17, yields

$$
\frac{\partial \epsilon_{\mathrm{e}}}{\partial t}+\nabla \cdot \mathbf{v}=\frac{1-t_{+}^{\mathrm{o}}}{F} j \hat{V}+\frac{1}{2 F} j_{\mathrm{o}} \hat{V}_{\mathrm{o}}
$$

Two scenarios may result from the reaction-induced electrolyte volume reduction during discharge: $(i)$ there is excess electrolyte available in the head space located at the top of the cell so that the cell is fully filled with the electrolyte all the time; and (ii) there is no excess electrolyte present, causing the electrode to dry out partially and become electrochemically inactive with time. In case $i$, which is the usual situation, the following holds true throughout the cell

$$
\epsilon_{\mathrm{e}}+\epsilon_{\mathrm{s}}=1
$$

Summing Eq. 18 and Eq. 16 and recognizing Eq. 19 results in

$$
\nabla \cdot \mathbf{v}=\frac{1-t_{+}^{\mathrm{o}}}{F} j \hat{V}+\frac{1}{2 F} j_{\mathrm{o}}\left(\hat{V}_{\mathrm{o}}-2 \hat{V}_{\mathrm{LiCl}}\right)
$$

Equation 20 represents the continuity equation of the liquid electrolyte and, when coupled with the electrolyte momentum equation, can be used to solve for the electrolyte flow field.

By integrating Eq. 20 over the whole cell and noting the fact that the reaction current, $j$, cancels in the anode and cathode, one obtains

$$
\int_{x=0}^{\mathrm{L}}(v)_{y=\mathrm{H}} d x=\frac{H L_{\mathrm{c}}<j_{\mathrm{O}}>}{2 F}\left(\hat{V}_{\mathrm{o}}-2 \hat{V}_{\mathrm{LiCl}}\right)
$$

where $v_{y=\mathrm{H}}$ is the electrolyte velocity at the top surface of the cell, $H$ is the electrode height, $L_{\mathrm{c}}$ is the thickness of the cathode, and $\left\langle j_{\mathrm{o}}\right\rangle$ is the volume-averaged reaction current within the cathode. Equation 21 indicates that the total amount of the electrolyte drawn into the cell from the top head space is directly proportional to the volume reduction of active materials inside the cell.

In case $i i$, there is no electrolyte replenishing the cell and thus the cell partly dries out as the discharge proceeds. The electrolyte velocity, $v_{y=\mathrm{H}}$, at the free surface of electrolyte is then equal to the moving velocity of the receding interface, thus yielding

$$
\frac{1}{<H>} \frac{d<H>}{d t}=\frac{L_{\mathrm{c}}}{L} \frac{<j_{\mathrm{o}}>}{2 F}\left(\hat{V}_{\mathrm{o}}-2 \hat{V}_{\mathrm{LiCl}}\right)
$$

where $H$ is the local electrolyte height and the symbol $<>$ denotes its average across the cell. Integrating Eq. 22 with time yields.

$$
<H>=H^{\mathrm{o}} \exp \left[\frac{L_{\mathrm{c}}}{2 F L}\left(\hat{V}_{\mathrm{o}}-2 \hat{V}_{\mathrm{LiCl}}\right) \int_{0}^{\mathrm{t}}<j_{\mathrm{o}}>d t^{\prime}\right]
$$

where $\langle H\rangle$ is the average electrolyte height in the cell and $H^{\mathrm{o}}$ is the initial height. No electrochemical reactions take place where $y>H$ due to the absence of electrolyte. Because Eq. 19 is valid for $y \leq H$, Eq. 20 still holds true in this region of $y \leq H$. Equation 23 allows one to calculate the change in the domain geometry as the electrolyte recedes and hence enables regridding of the mesh in numerical simulations. A moving boundary numerical technique is warranted to simulate case $i$.

For creeping flow of the electrolyte through a porous electrode, the momentum equation in Table I of Wang et al. ${ }^{9}$ reduces to the familiar Darcy's law; i.e.

$$
\mathbf{v}=-\frac{K}{\mu} \nabla p
$$

where $p$ is the pressure, $K$ is the permeability of the porous medium, and $\mu$ is the dynamic viscosity of the electrolyte. Substituting Eq. 24 into Eq. 20 results in

$$
\nabla \cdot\left(\frac{K}{\mu} \nabla p\right)+\frac{1-t_{+}^{\mathrm{o}}}{F} j \hat{V}+\frac{1}{2 F} j_{\mathrm{o}}\left(\hat{V}_{\mathrm{o}}-2 \hat{V}_{\mathrm{LiCl}}\right)=0
$$

This equation is solved for the pressure field in the electrolyte, with the permeability evaluated by the Kozeny-Carman relation ${ }^{11}$

$$
K=\frac{\epsilon^{3} d^{2}}{180(1-\epsilon)^{2}}
$$

where $d$ is the diameter of particles that make up the porous cathode. Assuming spherical particles, $d$ is related to the specific interfacial 
surface area and the porosity by $d=6 \epsilon / \mathrm{a}$. Once the pressure field is determined, the electrolyte flow field can be calculated from Eq. 24.

Equations 4, 13, 14, 16, and 25 form a complete set of governing equations for five unknowns: $c, \phi_{\mathrm{e}}, \phi_{\mathrm{s}}, \epsilon_{\mathrm{s}}$, and $p$. Their corresponding initial and boundary conditions are as follows

Initial conditions

$$
c=c^{\circ} \text { and } \epsilon_{\mathrm{s}}=1-\epsilon_{\mathrm{e}}{ }^{\mathrm{o}} \quad \text { at } t=0
$$

Boundary conditions

Concentration

$$
\left\{\begin{array}{l}
c=c^{\mathrm{o}} \text { for case } i \text { and } \frac{\partial \mathrm{c}}{\partial \mathrm{y}}=0 \text { for case } i \text { at } y=H \\
\frac{\partial c}{\partial n}=0 \text { at other boundaries }
\end{array}\right.
$$

$$
\text { Pressure } \quad\left\{\begin{array}{l}
p=0 \text { at } y=H \\
\frac{\partial p}{\partial n}=0 \text { at other boundaries }
\end{array}\right.
$$

Potential

$$
\left\{\begin{array}{l}
\frac{\partial \phi_{\mathrm{e}}}{\partial n}=0 \text { at all boundaries } \\
\frac{\partial \phi_{\mathrm{s}}}{\partial y}=0 \text { at } y=0 \text { and } H \\
\phi_{\mathrm{s}}=0 \text { at } x=0 \\
\phi_{\mathrm{s}}=V \text { for potentiostatic discharge } \\
-\sigma^{\text {eff }} \frac{\partial \phi_{\mathrm{s}}}{\partial x}=\frac{I}{A} \text { for galvanic discharge } \\
-\sigma^{\text {eff }} \frac{\partial \phi_{\mathrm{s}}}{\partial x}=\frac{\phi_{\mathrm{s}}}{R_{\mathrm{o}} A} \text { for constant load discharge }
\end{array}\right\} \text { at } x=L
$$

where $V, I$, and $R_{\mathrm{o}}$ are the applied cell voltage, current, and load, respectively, and $A$ is the projected effective electrode area.

Numerical procedures.-The conservation equations, Eq. 4, 13, 14,16 , and 25 , are discretized using a finite-volume method ${ }^{12}$ and solved using a general-purpose CFD code. Details have been given in the previous work. ${ }^{9,13}$ It should be mentioned that stringent numerical tests were performed to ensure that the solutions were independent of the grid size and time step. It was found that a $47 \times$ 32 mesh provides sufficient spatial resolution and the time step normally ranges from 600 to $1800 \mathrm{~s}$, except for the very beginning and the end of discharge where smaller time steps are required. The equations were solved as a simultaneous set, and the solution was considered to be convergent when the relative error in each field between two consecutive iterations was less than $10^{-5}$. A typical transient simulation for two-dimensional problems with electrolyte flow required about 30 min of CPU time on an SGI Octane workstation or a $400 \mathrm{MHz}$ PC.

\section{Results and Discussion}

Experimental verification.-To validate the numerical model developed in the preceding section, comparisons were made with the experimental data most recently reported by Jain et al. ${ }^{6}$ for $\mathrm{Li} / \mathrm{SOCl}_{2}$ cells over a range of temperatures. The parameters used in the simulations reported here were taken from Jain et al., ${ }^{6}$ and are summarized in Table I and Appendix A. For all simulations shown in this paper, there is an ample supply of electrolyte in the head space such that the top of the cell does not become depleted.

Figure 2 compares the predicted cell potential curves with the experimental results ${ }^{6}$ for a constant load discharge at $50 \Omega$. Good agreement can be seen for all three operating temperatures, indicating that the present two-dimensional model can accurately predict the cell performance. Consistent with the experimental data from Jain

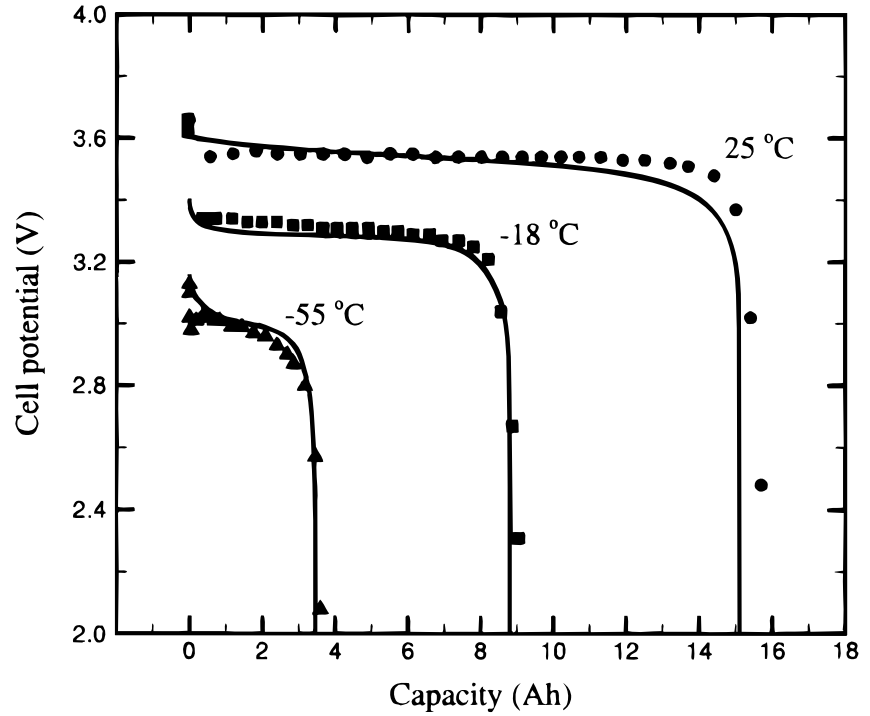

Figure 2. Comparison of experimental and predicted discharge curves for a $50 \Omega$ load at $-55,-18$, and $25^{\circ} \mathrm{C}$. The symbols represent the experimental data from Jain et al., ${ }^{6}$ while the solid lines are the predicted results.

et al. ${ }^{6}$ the end of discharge is marked by a drastic drop in the cell potential. For all three temperatures shown in Fig. 2, the end of discharge is due to clogging of the front of the cathode with $\mathrm{LiCl}$ precipitate. It is also interesting to note that the modified one-dimensional model of Jain et al., ${ }^{5,6}$ which assumes that the electrolyte flows down from the head space into the cathode, produced nearly identical discharge curves. This fact prompts us to show that the present twodimensional model is reduced identically to the model of Jain et al..$^{5,6}$ under one-dimensional assumptions. Appendix B describes this derivation in detail and concludes that the two key equations in Jain and Weidner's one-dimensional model ${ }^{5}$ are indeed recovered.

Visualizing electrolyte flow.-A unique advantage of detailed two-dimensional computer simulation is the ability to visualize the electrolyte flow inside a battery, thus providing much insight into the battery internal operation during discharge. This capability, while highly desired for fundamental battery research, is difficult if not impossible to realize by pure experimentation.

The electrolyte flow fields simulated by the present two-dimensional model are displayed in Fig. 3 and 4 at four representative instants of time during battery discharge at -18 and $-55^{\circ} \mathrm{C}$, respectively. These plots are in the form of streamlines (i.e., lines everywhere tangent to the velocity vector at a given instant). The background shading in Fig. 3 and 4 represents the magnitude of the velocity component in the vertical direction. For illustrative purposes, the width of the cell relative to its height depicted in these two figures has been expanded by a factor of 20 .

Figure 3 clearly shows that the electrolyte flow induced by volume reduction due to the electrochemical reaction is in the horizontal direction from the separator into the cathode during the early parts of the discharge. This is because the separator is highly porous and remains so during most of the discharge. Consistent with the model developed by Tsaur and Pollard, ${ }^{3}$ the separator essentially serves as a reservoir to feed excess electrolyte into the cathode. This flow pattern persists until the front side of the cathode becomes nearly plugged, thus leading to blockage of electrolyte flow from the separator.

As the front of the electrode becomes plugged, progressively more of the electrolyte needed to fill voids created by the electrochemical reaction in the cathode comes from the top permeable surface. The transition in the flow patterns is illustrated in Fig. 3 at $t=$ $127 \mathrm{~h}$. As the end of discharge approaches (i.e., at $t=135 \mathrm{~h}$ ), the front side of the cathode is nearly plugged so that the electrolyte flows in the separator and cathode are separated. Within the separator, the electrolyte volume begins to expand due to the continual $\mathrm{Li}^{+}$ 
production from the anode, causing overflow of the electrolyte toward the top of the cell, although the magnitude of this velocity is small. By contrast, the electrolyte is drawn into the top of the cathode (shown in the upper right corner of each streamline plot in Fig. 3) and flows toward the reaction sites at the separator-cathode interface, where volume reduction continues to occur due to the cathode reaction. The filling of cathode with electrolyte from the head space toward the end of discharge is consistent with the model developed by Jain et al. ${ }^{5,6}$ In reality then, the electrolyte flow pattern is a combination of the two idealized, one-dimensional models. The net result is that for the discharge curves shown here, the velocity field does not significantly impact the cell voltage. Therefore, a onedimensional model simulates the discharge curves as well as a twodimensional model. However, this may not be true for all sets of operating parameters. In addition, the two-dimensional model reveals complex processes that are occurring in the cell that cannot be captured by a one-dimensional model.

The electrolyte flow fields during discharge at $-55^{\circ} \mathrm{C}$, as displayed in Fig. 4, exhibit the same features as in the case of $-18^{\circ} \mathrm{C}$, except that the flow becomes two-dimensional at earlier stages of discharge (see the image at the upper right corner of Fig. 4). This is because the electrochemical reaction inside the cathode is more nonuniform at a lower cell temperature and clogging of the front surface occurs sooner. Hence, electrolyte flow from the top of the cell is more nonuniform.

Electrolyte concentration, reaction rate, and electrode porosity distributions.-Figures 5 and 6 show the predicted electrolyte concentration profiles at the half height of the cell and how they evolve with time in the cases of -18 and $-55^{\circ} \mathrm{C}$, respectively. The concentration increases from its initial value in the separator owing to the $\mathrm{Li}^{+}$production from the anode, whereas electrolyte is being consumed in the cathode. As discharge proceeds, $\mathrm{LiCl}$ precipitate begins to fill the pores of the cathode and the concentration gradient becomes greater at the separator-cathode interface due to the lower porosity of this region, which significantly reduces the effective diffusion coefficient. Electrolyte transport thus becomes more difficult at later times. In the discharge case of $-18^{\circ} \mathrm{C}$ (i.e., Fig. 5), the sep-
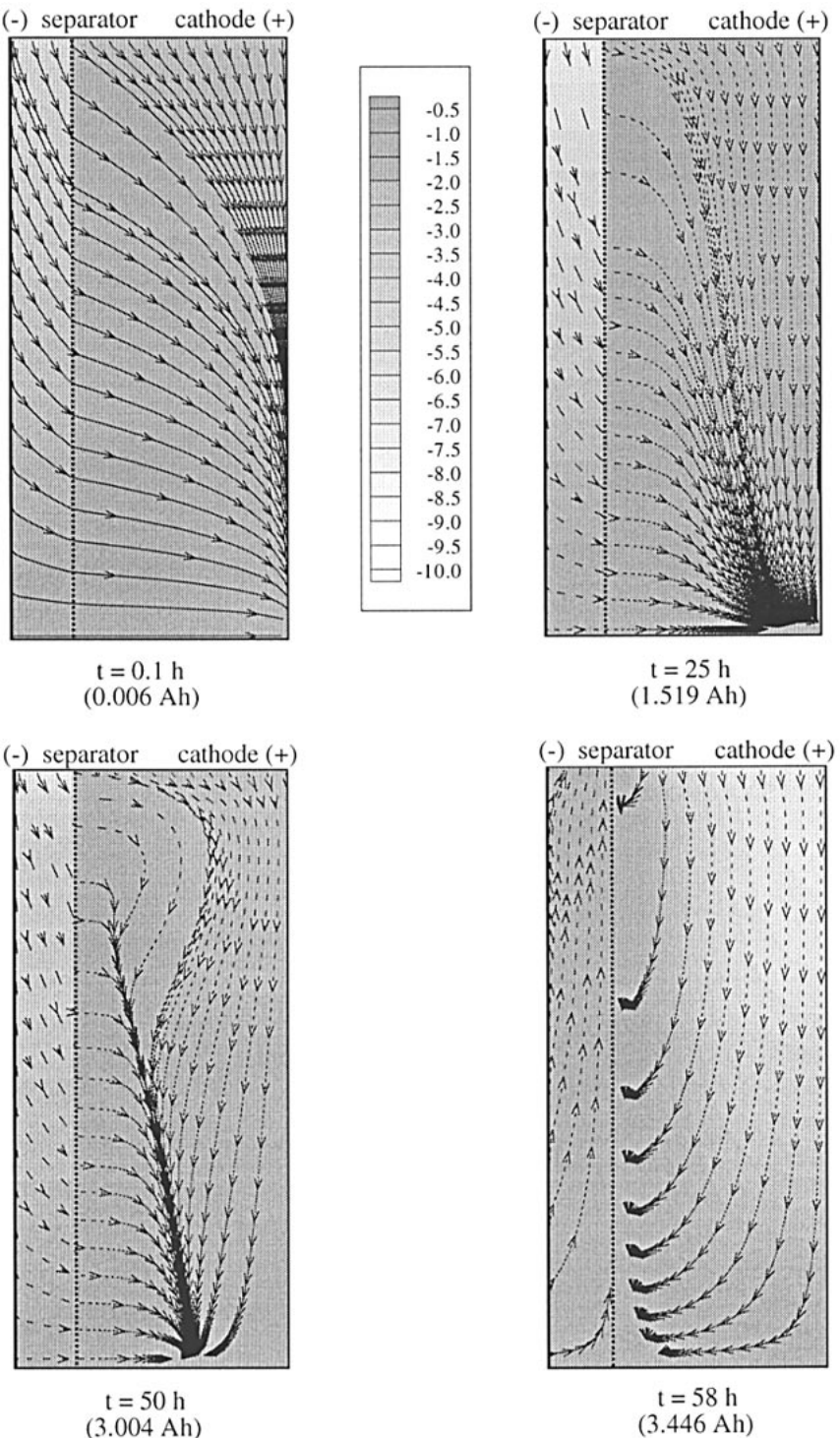

Figure 4. Electrolyte flow within the cell, streamline plot. The cell is discharged at $-55^{\circ} \mathrm{C}$ with a $50 \Omega$ load and the end of discharge is $58.2 \mathrm{~h}$. The background shading represents the magnitude of the velocity component in the vertical direction, with the corresponding values shown on the side bar in $10^{-6} \mathrm{~cm} / \mathrm{s}$. For illustrative purposes, the width of the cell relative to its height has been expanded by a factor of 20 . 


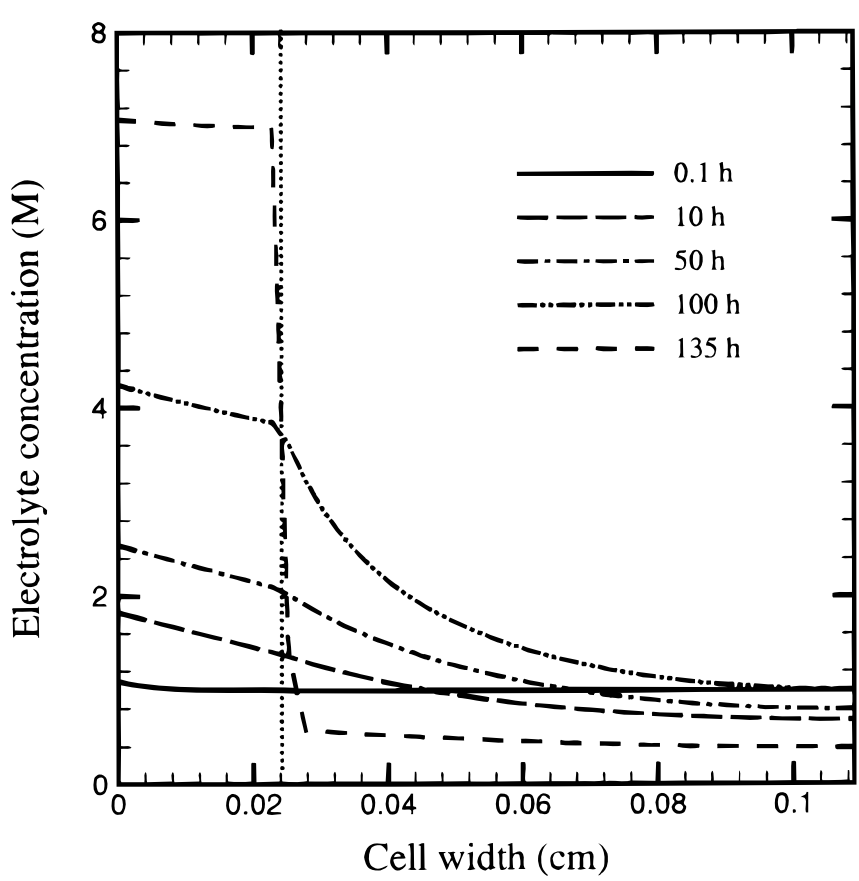

Figure 5. Electrolyte concentration profiles at the half height of the electrode when the cell is discharged with a $50 \Omega$ load at $-18^{\circ} \mathrm{C}$. The electrolyte concentration shown here is in moles per liter $(\mathrm{M})$, and the end of discharge is $135.2 \mathrm{~h}$.

arator-cathode interface is completely shut off at $t=135 \mathrm{~h}$ and the electrolyte becomes nearly depleted within the cathode, leading to the end of discharge. The end of discharge in the case of $-55^{\circ} \mathrm{C}$ occurs at around $58 \mathrm{~h}$ (Fig. 6).

The reaction rate profiles within the cathode, also at the half height of the cell, are displayed in Fig. 7 and 8 at various times for -18 and $-55^{\circ} \mathrm{C}$, respectively. At early stages of discharge, the reac-

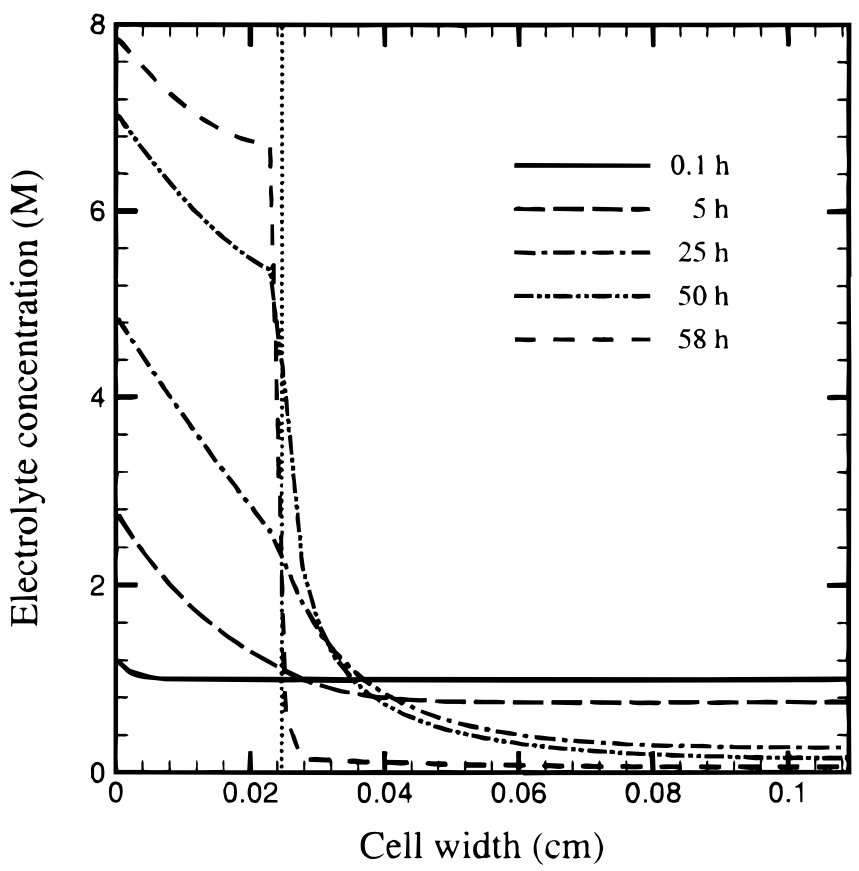

Figure 6. Electrolyte concentration profiles at the half height of the electrode when the cell is discharged with a $50 \Omega$ load at $-55^{\circ} \mathrm{C}$. The electrolyte concentration shown here is in moles per liter $(\mathrm{M})$, and the end of discharge is $58.2 \mathrm{~h}$.
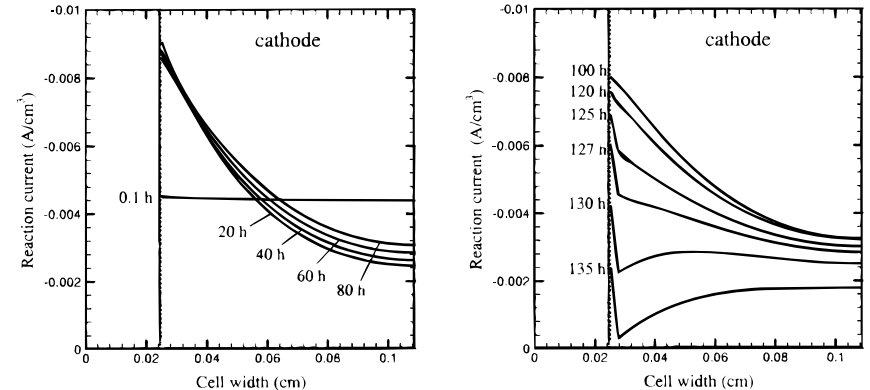

Figure 7. Reaction current profiles at the half height of the electrode when the cell is discharged with a $50 \Omega$ load at $-18^{\circ} \mathrm{C}$. The end of discharge is $135.2 \mathrm{~h}$.

tion rate has its maximum at the front and its minimum at the back of the cathode, as typically found in most batteries. The profile reaches a pseudo-steady state around $80-100 \mathrm{~h}$ in the case of $-18^{\circ} \mathrm{C}$ discharge (i.e., Fig. 7). Thereafter, the reaction rate along the separator-cathode interface decreases because the local surface area available for reaction is reduced due to $\mathrm{LiCl}$ precipitation. Note that the volumetric reaction rate depicted in Fig. 7 and 8 is a product of the transfer current density and the electrochemically active surface area per unit volume. The reduction in the reaction rate as the pores at the front of the cathode become plugged leads to a minimum in the profile in the vicinity of the cathode front side, as can be seen from both Fig. 7 and 8.

Figure 9 shows the final porosity profiles at the half height of the cell when the cell is fully discharged at $-55,-18$, and $25^{\circ} \mathrm{C}$, respectively. It is clearly seen that the cell lifetime at all three temperatures is limited by pore plugging or clogging on the front of the cathode where the porosity goes to zero. Furthermore, the final porosity averaged across the cathode, denoting the amount of $\mathrm{LiCl}$ precipitate, is a measure of the cell capacity. The higher the cell temperature, the more uniform (and lower) the electrode porosity is before the front side of the cathode becomes clogged, and hence, the higher capacity. In contrast, at a lower temperature $\left(e . g .,-55^{\circ} \mathrm{C}\right)$ only the very front portion of the cathode is utilized and becomes plugged, causing an earlier end of discharge.

\section{Conclusions}

A two-dimensional model of a $\mathrm{Li} / \mathrm{SOCl}_{2}$ battery has been developed based on the multiphase modeling framework of Wang et al. ${ }^{9}$ The present model includes, among other features, the electrolyte flow induced by the volume reduction that occurs with the electrochemical reactions in the $\mathrm{Li} / \mathrm{SOCl}_{2}$ battery. The model predictions were compared to the experimental data with good agreement over a range of cell temperatures. More significantly, the two-dimensional model for the first time allowed numerical visualization of the electrolyte flow occurring inside the battery. This capability, in conjunction with the computer animation technique, yielded much insight into the battery
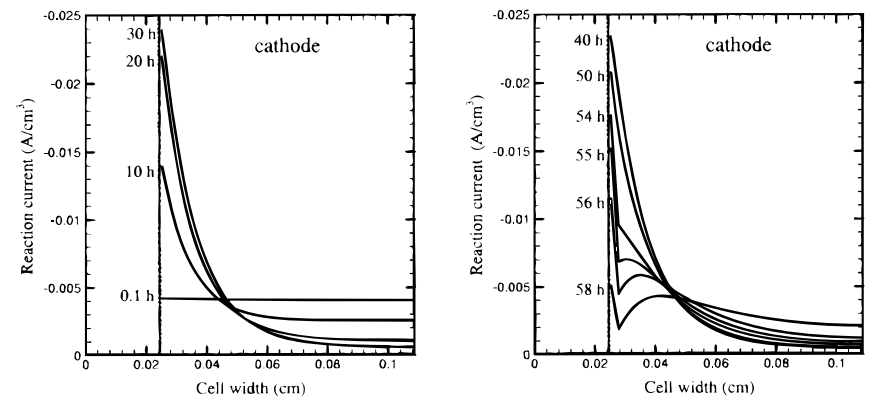

Figure 8. Reaction current profiles at the half height of the electrode when the cell is discharged with a $50 \Omega$ load at $-55^{\circ} \mathrm{C}$. The end of discharge is $58.2 \mathrm{~h}$. 


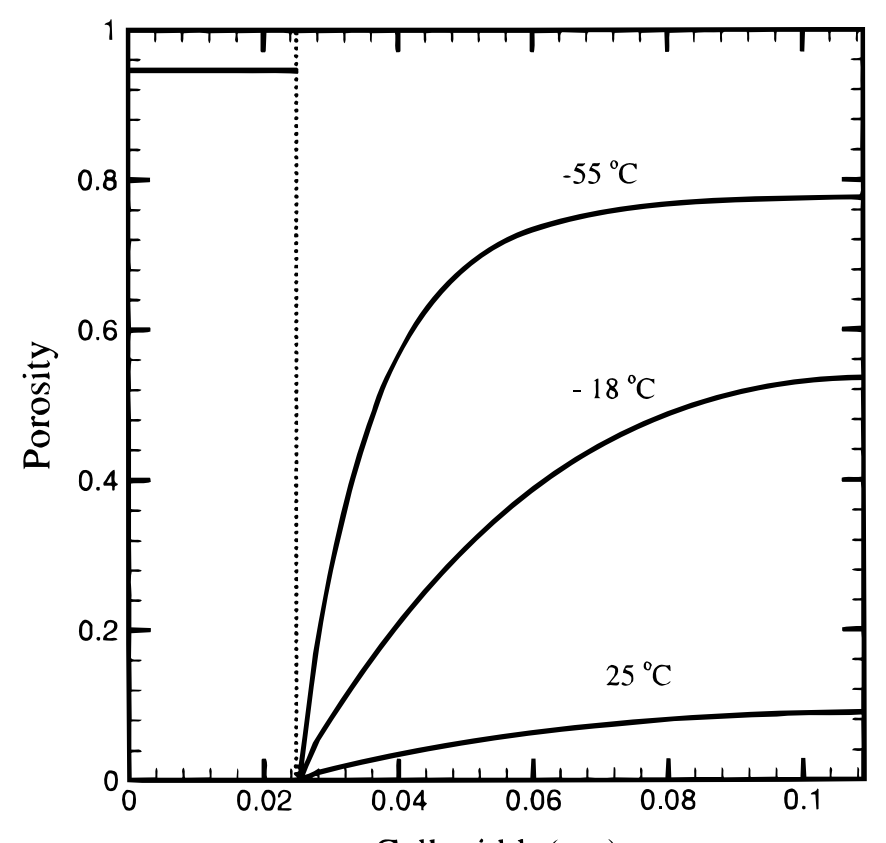

Cell width $(\mathrm{cm})$

Figure 9. Porosity profiles along the half height of the electrode at the end of discharge with various temperatures.

internal operation and provided convincing evidence to justify the assumptions made in the earlier one-dimensional models. ${ }^{3-6}$

\section{Acknowledgments}

C.Y.W. acknowledges the partial support of this work by a NSF CAREER Award, grant no. CTS-9733662. Sandia is a multiprogram laboratory operated by Sandia Corporation, a Lockheed Martin Company, for the United States Department of Energy under contract DE-AC04-94AL85000.

The University of South Carolina assisted in meeting the publication costs of this article.

\section{Appendix A}

\section{Property Correlations ${ }^{6}$}

1. Diffusion coefficient of $\mathrm{LiAlCl}_{4}-\mathrm{SOCl}_{2}$ electrolyte

$$
D=1.726 \times 10^{16} \exp \left(-\frac{2.315 \times 10^{4}}{T}+\frac{2.395 \times 10^{6}}{T^{2}}\right)
$$

2. Ionic conductivity of $\mathrm{LiAlCl}_{4}-\mathrm{SOCl}_{2}$ electrolyte

$$
\kappa=\left\{\begin{array}{l}
9.79 c \exp \left(2039.09 c-2.5055 \times 10^{5} c^{2}\right) \\
1.6 \times 10^{-2} \exp \left(1.63 \times 10^{3} c\right) \\
\left(2.11 \times 10^{-2}-2.53 c\right) \exp \left(1.63 \times 10^{3} c\right) \\
\exp \left[-\frac{\left(4.88 \times 10^{5} c-71.73\right)}{T}\right] \text { for } c<1.8 \mathrm{M} \\
\exp \left[-\frac{\left(4.88 \times 10^{5} c-71.73\right)}{T}\right] \text { for } 1.8 \mathrm{M} \leq \mathrm{c}<2.0 \mathrm{M} \\
\exp \left[-\frac{\left(4.88 \times 10^{5} c-71.73\right)}{T}\right] \text { for } c>2.0 \mathrm{M}
\end{array}\right.
$$

3. Exchange current density for the anode reaction

$$
i_{\mathrm{o} 1, \mathrm{ref}}=1.157 \times 10^{3} \exp \left(-\frac{4641}{T}\right)
$$

4. Exchange current density for the cathode reaction

$$
i_{\mathrm{o} 2 \text {,ref }}=2.5 \times 10^{3} \exp \left(-\frac{5500}{T}\right)
$$

5. Open-circuit voltage of $\mathrm{Li} / \mathrm{SOCl}_{2}$ cell

$$
E=3.723+T \frac{d E}{d T}
$$

\section{Appendix B}

Reduction to Jain and Weidner's One-Dimensional Model ${ }^{5}$

Equation 4 in the present two-dimensional model can be reduced to Jain and Weidner's model ${ }^{5}$ under two assumptions

1. The cell is one-dimensional so that all variables are uniform along the electrode height.

2. The electrolyte flow within the cell is caused only by the net volume reduction of the electrolyte due to the electrochemical reaction expressed by Eq. 3. Integrating Eq. 4 over the electrode height results in

$$
\begin{aligned}
\int_{0}^{H}\left[\frac{\partial\left(\epsilon_{\mathrm{e}} c\right)}{\partial t}+\frac{\partial\left(v_{x} c\right)}{\partial x}+\frac{\partial\left(v_{y} c\right)}{\partial y}\right] d y & =\int_{0}^{H}\left[\frac{\partial}{\partial x}\left(D^{\mathrm{eff}} \frac{\partial c}{\partial x}\right)\right. \\
& \left.+\frac{\partial}{\partial y}\left(D^{\mathrm{eff}} \frac{\partial c}{\partial y}\right)+\frac{1-t_{+}^{\mathrm{o}}}{F} j\right] d y
\end{aligned}
$$

Under assumption 1, Eq. B-1 is then simplified to

$$
\frac{\partial\left(\epsilon_{\mathrm{e}} c\right)}{\partial t}+\frac{\partial\left(v_{x} c\right)}{\partial x}=\frac{\partial}{\partial x}\left(D^{\mathrm{eff}} \frac{\partial c}{\partial x}\right)+\frac{1-t_{+}^{\mathrm{o}}}{F} j-\frac{N_{y=H}}{H}
$$

where

$$
N_{y=H}=\left(-D^{\mathrm{eff}} \frac{\partial c}{\partial y}+v_{y} c\right)_{y=H}
$$

representing the net species flux from the top permeable surface. To arrive at Eq. B-2, use has been made of the no-flux boundary condition at the cell bottom surface.

For the case where the excess electrolyte, with concentration $c^{\mathrm{o}}$, enters the electrode, the molar flux of the electrolyte at $y=H$ can be expressed, according to assumption 2 , as

$$
N_{y=H}=c^{\mathrm{o}} \frac{j_{\mathrm{o}}}{2 F}\left(\hat{V}_{\mathrm{o}}-2 \hat{V}_{\mathrm{LiCl}}\right) H
$$

Noting that

$$
j_{\mathrm{o}}=j=\frac{\partial i_{\mathrm{e}}}{\partial \mathrm{x}}
$$

Eq. B-4 thus becomes

$$
\frac{N_{y=H}}{H}=\frac{j}{F} \frac{c^{\mathrm{o}}}{2}\left(\hat{V}_{\mathrm{o}}-2 \hat{V}_{\text {Licl }}\right)
$$

For the case where no excess electrolyte is present at the top and the free surface of the electrolyte recedes due to the electrolyte volume reduction, Eq. B-3 is reduced to

$$
N_{y=H}=\left(v_{y} c\right)_{y=H}
$$

where $H$ is the moving electrolyte height, the velocity of which varies in accordance with the amount of volume reduction occurring inside the cell; namely

$$
\frac{v_{y}}{\epsilon_{\mathrm{e}}}=\frac{j}{2 F}\left(\hat{V}_{\mathrm{o}}-2 \hat{V}_{\mathrm{LiCl}}\right) H
$$

Combining Eq. B-7 with Eq. B-8 yields

$$
\frac{N_{y=H}}{H}=\frac{j}{F} \frac{\epsilon_{\mathrm{e}} c}{2}\left(\hat{V}_{\mathrm{o}}-2 \hat{V}_{\mathrm{LiCl}}\right)
$$

Substituting Eq. B-6 or Eq. B-9 into Eq. B-2 and making proper arrangements result in 


$$
\begin{aligned}
\epsilon_{\mathrm{e}} \frac{\partial c}{\partial t}+c \frac{\partial \epsilon_{\mathrm{e}}}{\partial \mathrm{x}}=-\frac{\partial}{\partial x}\left(-D^{\mathrm{eff}} \frac{\partial c}{\partial x}+\frac{i_{\mathrm{e}} t_{+}^{\mathrm{o}}}{F}+c v_{x}\right) \\
+\frac{j}{F}\left[1-\frac{c^{\mathrm{o}}}{2}\left(\hat{V}_{\mathrm{o}}-2 \hat{V}_{\mathrm{Licl}}\right)\right]
\end{aligned}
$$

for the case where excess electrolyte is available above the cell, or

$$
\begin{aligned}
\epsilon_{\mathrm{e}} \frac{\partial c}{\partial t}+c \frac{\partial \epsilon_{\mathrm{e}}}{\partial \mathrm{x}}=-\frac{\partial}{\partial x}\left(-D^{\mathrm{eff}} \frac{\partial c}{\partial x}+\frac{i_{\mathrm{e}} t_{+}^{\mathrm{o}}}{F}+c v_{x}\right) \\
+\frac{j}{F}\left[1-\frac{\epsilon_{\mathrm{e}} c}{2}\left(\hat{V}_{\mathrm{o}}-2 \hat{V}_{\mathrm{LiCl}}\right)\right]
\end{aligned}
$$

for the case where there is no excess electrolyte in the battery.

Equations B-10 and B-11 are identical to the one-dimensional species conservation equations developed by Jain and Weidner. ${ }^{5}$ In the parametric range examined in the present paper, the one-dimensional assumption of horizontal electrolyte flow appears reasonable as verified by the two-dimensional flow field presented in this paper. However, caution should be exercised that the one-dimensional model may not hold true in other circumstances.

\section{List of Symbols}

projected effective electrode area, $\mathrm{cm}^{2}$ specific interfacial area at the anode, $\mathrm{cm}^{2} / \mathrm{cm}^{3}$ specific interfacial area at the cathode, $\mathrm{cm}^{2} / \mathrm{cm}^{3}$ concentration of a species, $\mathrm{mol} / \mathrm{cm}^{3}$ diffusion coefficient of the electrolyte, $\mathrm{cm}^{2} / \mathrm{s}$ diameter of particles that make up the porous electrode, $\mathrm{cm}$ Faraday's constant, $96487 \mathrm{C} / \mathrm{mol}$ effective electrode height, $\mathrm{cm}$ applied current, A transfer current density of reaction $\mathrm{j}$ at the electrode/electrolyte interface, $\mathrm{A} / \mathrm{cm}^{2}$

exchange current density of reaction $\mathrm{j}, \mathrm{A} / \mathrm{cm}^{2}$ volumetric reaction current, $\mathrm{A} / \mathrm{cm}^{3}$ permeability of the porous medium, $\mathrm{cm}^{2}$ cell width, $\mathrm{cm}$ thickness of the cathode, $\mathrm{cm}$ electrolyte pressure, $\mathrm{g} / \mathrm{cm}^{2}$ universal gas constant, $8.3143 \mathrm{~J} / \mathrm{mol} \mathrm{K}$ applied load, $\Omega$ absolute temperature of the cell, $\mathrm{K}$ time, $s$ $t_{+}^{\mathrm{o}} \quad$ transference number of lithium ion with respect to the volume-averaged velocity

$U_{\mathrm{j}} \quad$ open-circuit potential of electrode reaction $\mathrm{j}, \mathrm{V}$

v volume-averaged velocity vector, $\mathrm{cm} / \mathrm{s}$

$V_{\mathrm{i}} \quad$ velocity component in the i direction, $\mathrm{cm} / \mathrm{s}$

$\hat{V}$ partial molar volume of a species, $\mathrm{cm}^{3} / \mathrm{mol}$

$x \quad x$ coordinate in Cartesian coordinate system, $\mathrm{cm}$

$y \quad y$ coordinate in Cartesian coordinate system, $\mathrm{cm}$

Greek

$\alpha_{\mathrm{aj}}, \alpha_{\mathrm{cj}}$ anodic and cathodic transfer coefficients of reaction $\mathrm{j}$

$\epsilon \quad$ porosity of a porous medium or volume fraction of a phase

$\zeta \quad$ morphology correction index in Eq. 11

$\eta_{\mathrm{j}} \quad$ surface overpotential of reaction $\mathrm{j}, \mathrm{V}$

$\kappa \quad$ ionic conductivity of the electrolyte, $\mathrm{S} / \mathrm{cm}$

$\kappa_{D} \quad$ diffusional conductivity, $\mathrm{A} / \mathrm{cm}$

$\mu \quad$ dynamic viscosity of the electrolyte, $\mathrm{g} \mathrm{cm} / \mathrm{s}$

$\sigma \quad$ electronic conductivity of the solid matrix, $\mathrm{S} / \mathrm{cm}$

$\phi \quad$ phase potential, $\mathrm{V}$

Subscript

e electrolyte phase

o solvent

ref at reference conditions

s solid phase

Superscript

o initial value

eff effective

\section{References}

1. S. Szpak, C. J. Gabriel, and J. R. Driscoll, Electrochim. Acta, 32, 239 (1987).

2. Y. I. Cho, J. Electrochem. Soc., 134, 771 (1987).

3. K. Tsaur and R. Pollard, J. Electrochem. Soc., 131, 975 (1984).

4. T. I. Evans, T. V. Nguyen, and R. E. White, J. Electrochem. Soc., 136, 328 (1989).

5. M. Jain and J. W. Weidner, J. Electrochem. Soc., 146, 1370 (1999).

6. M. Jain, G. Nagasubramanian, R. G. Jungst, and J. W. Weidner, J Electrochem. Soc., 146, 4023 (1999).

7. N. A. Fleischer and R. J. Ekern, J. Power Sources, 10, 179 (1983).

8. P. Chenebault, D. Vallin, J. Thevenin, and R. Wiart, J. Appl. Electrochem., 18, 625 (1988).

9. C. Y. Wang, W. B. Gu, and B. Y. Liaw, J. Electrochem. Soc., 145, 3407 (1998)

10. J. S. Dunning, D. N. Bennion, and J. Newman, J. Electrochem. Soc., 120, 906 (1973)

11. A. E. Scheidegger, The Physics of Flow Through Porous Media, Macmillan Publishing, New York (1960).

12. S. V. Patankar, Numerical Heat Transfer and Fluid Flow, Hemisphere, Washington, DC (1980).

13. W. B. Gu, C. Y. Wang, and B. Y. Liaw, J. Power Sources, 75/1, 154 (1998).

14. S. Szpak and H. V. Venkatasetty, J. Electrochem. Soc., 131, 961 (1984). 